\title{
When sleeve gastrectomy fails: adding a laparoscopic adjustable gastric band to increase restriction
}

\author{
Alexander J. Greenstein · Anthony J. Vine • \\ Brian P. Jacob
}

Received: 20 December 2007/Accepted: 3 May 2008/Published online: 1 January 2009

(C) Springer Science+Business Media, LLC 2008

\begin{abstract}
The use of laparoscopic sleeve gastrectomy (LSG) as a procedure for morbid obesity has recently increased. The LSG procedure is used most often as a part of a biliopancreatic diversion with duodenal switch (BPDDS) or as a first stage that can be converted to a BPDDS or Roux-en-Y gastric bypass (RYGB) [1, 2]. However, the surgical indications for LSG have rapidly expanded, and some centers use the sleeve as the primary operation for morbid obesity [3, 4].

The utility of LSG as a primary procedure is controversial, with consensus lacking in the literature. Whether the etiology of failed sufficient weight loss is the result of an inadequate sleeve or attributable to dilation or hypertrophy of the sleeve, the incidence of failed sleeve gastrectomies may be significant.

In the treatment of a patient with a failed LSG, the options typically include creation of a tighter sleeve or conversion to biliopancreatic diversion or RYGB [5]. These procedures, however, are complex and can carry significant morbidity.

The authors report a case of a morbidly obese 42-yearold man who failed to lose sufficient weight after an LSG. Because the patient was dependent on several oral antipsychotic medications, he refused any malabsorptive
\end{abstract}

This video manuscript was presented at the 2008 Society of the American Gastrointestinal and Endoscopic Surgeons (SAGES) Meeting, 12 April 2008, Philadelphia, PA.

Electronic supplementary material The online version of this article (doi:10.1007/s00464-008-0293-2) contains supplementary material, which is available to authorized users.

A. J. Greenstein · A. J. Vine · B. P. Jacob $(\bowtie)$

Department of Surgery, The Mount Sinai Medical Center,

1010 Fifth Avenue, New York, NY 10028, USA

e-mail: Brian.Jacob@mssm.edu procedure, and a decision was made to proceed with laparoscopic adjustable gastric banding (LAGB). The case proceeded successfully, and at this writing, 9 months after surgery, the patient has achieved a $57 \%$ excess weight loss from an original weight of $390 \mathrm{lb}$.

The insertion of an LAGB into its normal anatomic position is feasible after a sleeve gastrectomy, and its use can induce sufficient restriction and weight loss results equivalent to those of a sleeve or band alone and possibly better.

Keywords Band · Gastrectomy - Laparoscopic . Obesity $\cdot$ Revision $\cdot$ Sleeve

\section{References}

1. Hess DS, Hess DW (1998) Biliopancreatic diversion with a duodenal switch. Obes Surg 8:267-282

2. Marceau P, Hould FS, Simard S, Lebel S, Bourque RA, Potvin M, Biron S (1998) Biliopancreatic diversion with duodenal switch. World J Surg 22:947-954

3. Baltasar A, Serra C, Perez N, Bou R, Bengochea M, Ferri L (2005) Laparoscopic sleeve gastrectomy: a multipurpose bariatric operation. Obes Surg 15:1124-1128

4. Hamoui N, Anthone GJ, Kaufman HS, Crookes PF (2006) Sleeve gastrectomy in the high-risk patient. Obes Surg 16:1445-1449

5. Gagner M, Rogula T (2003) Laparoscopic reoperative sleeve gastrectomy for poor weight loss after biliopancreatic diversion with duodenal switch. Obes Surg 13:649-654 